\title{
Life-course Oral Health
}

\author{
Prathip Phantumvanit \\ Thammasat University, Thailand \\ WHO Advisory Expert Panel for Oral Health
}

Oral health is the gateway to general health, life-course approach for health should include oral health. Healthy start in life will be a good investment for future healthy aging with emphasis on critical period such as pregnancy and early childhood. Oral health care approach should focus on different oral diseases or problems such as dental caries in children, periodontal diseases and tooth loss in adult and loss of tooth (oral) function in elderly. But oral health has been neglected therefore WHA-74 has approved the resolution for oral health as part of global health agenda. Oral health indicators will be a part of health promotion for NCD and a component of UHC for all age groups. Dental caries in pre-school children can be eliminated through primary prevention as limited sugar consumption with routine oral hygiene practice with fluoride toothpaste followed by secondary prevention especially early detection of early caries lesions, white spot lesions, with proper SDF application and finally effective tertiary prevention using non-invasive minimal intervention such as ART/SMART, friendly and positive attitude for oral health care in children. In adolescence and adult, periodontal disease is the common oral health problem which related to several NCD such as diabetes and heart diseases. Besides, tooth loss need to be replaced for better function especially in elderly. In all age groups, oral health care should cover routine early detection of early sign of oral diseases, follow by risk assessment to remove the causes with emphasis on effective oral health self-care and finally early treatment as necessary. Thereafter, systemic maintenance oral health care to monitor treatment outcomes and prevent recurrence oral diseases will motivate the patients with preventive oral care conscious. Through Life-course oral health, dentists should ambitiously aim to keep 28 teeth with healthy oral tissues in healthy aging.

Copyright (C) 2021. Korean Academy of Preventive Dentistry. All rights reserved.

This is an Open Access article distributed under the terms of the Creative Commons Attribution Non-Commercial License (http://creativecommons.org/licenses/ by-nc/4.0) which permits unrestricted non-commercial use, distribution, and reproduction in any medium, provided the original work is properly cited. 